\title{
Creativity Loading - Please Wait! Investigating the Relationship between Interruption, Mind Wandering and Creativity
}

\author{
Thorben Lukas Baumgart \\ University of Siegen, Germany \\ thorben.baumgart@student.uni-siegen.de
}

Frederike Marie Oschinsky

University of Siegen, Germany

frederike.oschinsky@uni-siegen.de

\author{
Michael Klesel \\ University of Siegen, Germany and \\ University of Twente, The Netherlands \\ michael.klesel@uni-siegen.de
}

Bjoern Niehaves

University of Siegen, Germany

bjoern.niehaves@uni-siegen.de

\begin{abstract}
With the advancement of information technologies, routine tasks are increasingly supported by information systems, which is why ideation and creativity is becoming more and more important. We know from many anecdotes that creative ideas emerge when our mind is wandering instead of being focused on the task at hand. Yet, most information systems that are used for work-related purposes offer only little opportunities for task-unrelated thoughts. In contrast, current literature shows that most information technology is designed to keep our attention. In order to better understand the value of mind wandering, we propose an experimental design that incorporates interruptions that vary in their length with the objective to stimulate episodes of mind wandering and thus positively impact creativity. We provide initial insights on how the experiment should designed and discuss implications for future research.
\end{abstract}

\section{Introduction}

To foster their creativity, scientists like Albert Einstein and Isaac Newton reported that by having task-unrelated thoughts, they were better able to solve problems [10]. Mind wandering is an attentional shift away from primarily tasks toward internal notions [59] that demonstrably helps create ideas by relieving the working memory [18]. Creativity on the other hand, is the ability to create an output which is novel and somehow useful or appropriate at the same time [62]. Literature repeatedly demonstrated the relationship between mind wandering and creativity as well as mind wandering and divergent thinking $[10,18,36]$.
Whereby divergent thinking describes the combination of different information in novel ways as a result from creative idea generation [29, 40]. When the aimless and effortless train of thoughts leads to unexpected ideas, people oftentimes experience "Aha!" or "Eureka!" moments which can yield in creative ideas [58].

Research suggests a high rate of mind wandering during everyday activities, which reaches up to 50 percent of our waking time [58]. While mentally shifting from topic to topic, individuals mostly process autobiographical information [63] regarding future or past events [11]. During mind-wandering episodes, we find a deviation of external information towards internal notions, which triggers divergent thinking and thus creativity [36].

While previous literature provides evidence on the importance of both mind wandering and creativity, little is known about the relationship of these two phenomena while using technology. Research about the characteristics of an information systems and its impact on the interplay between mind wandering and creativity is in its infancy. This gap is critical, because jobs increasingly require divergent thinking. In specific, creative thinking is considered as a basic prerequisite for successful practice in many domains dependent on innovation and novelty including product development and industrial design. Consequently, research that outlines managerial and design-relevant implications on fostering creativity can be considered an important step towards designing future workplaces.

In order to shed further light on the role of mind wandering, we draw from interruption literature in Information Systems (IS) research. In specific, we refer to the goal-activation model [6], which suggests that the length of interruption has an impact on 
whether a goal is maintained or not. Based on this idea, we suggest that a specific amount of interruption time has an effect on the ability to focus on a primary task and thus, individual goal persuasion. We suggest that individuals, who are interrupted for a considerable amount of time, are more likely to let their mind wander, compared to very short interruptions, which in turn leads to more divergent thinking and creativity.

Our contribution to IS research is valuable from a theoretical and practical perspective. On the one hand, we want to explain the connection between mind wandering and creativity with a technological focus, operationalized by means of different types of interruptions in an online environment. On the other hand, we seek to provide an impulse for design and seek to promote creativity through the design of the technology itself.

To address our goal, this paper is structured as follows. First, we examine current literature to give a brief overview of mind wandering as well as creativity both in IS research and related domains. Second, we propose a research model that allows us to explore the relationship between design, mind wandering, and creativity more thoroughly. Third, we describe an experimental study for investigating our hypotheses and add preliminary results. We conclude with a discussion of our results.

\section{Theoretical Background}

\subsection{Mind Wandering While Using Technology}

Mind wandering is a ubiquitous cognitive process [58]. It is described as "a shift in the contents of thoughts away from ongoing tasks and/or from events in the external environment to self-generated thoughts and feelings" (p. 488) [58], which arises from the naturally and aimlessly [55]. The train of thoughts is detached from the direct external environment and directed towards internal notions and ideas [63]. Also known as task-unrelated thought or daydreaming [57], mind wandering is described as an unguided state of disconnectedness from the environment [52], in which the way of thinking is barely controlled or focused, and thus free from constraints or boundaries [14, 15, 23]. Furthermore, mind-wandering thoughts are selfgenerated and mostly based on autobiographical experiences $[20,58]$.

The rate of mind wandering can be influenced by the commitment to a task. Smallwood et al. describe that the higher the level of engagement in a task, the lower the probability of a drift of thoughts [55]. Also, the general attitude to the task itself reveals different levels of a wandering mind. If the task is perceived as pleasant $(42.5 \%)$, the tendency for task-unrelated thoughts is much higher than for an unpleasant topic $(26.5 \%)$ [34].

To get into the state of mind wandering, sometime must pass, after interacting with the current surroundings. Risko et al. show that students during a lecture tend to task-unrelated thoughts mostly in the second half class [49], which indicates that the duration of time can trigger mind wandering. This effect can be enhanced by the individual level of motivation and interest in the topic [43], which is a significant indicator for being in a state of a wandering mind. Additionally, it is more likely to mind wander while resting, in non-demanding circumstances and during task-free activities [13, 46, 61].

As mind wandering is an inattentive, taskunrelated train of thoughts, negative effects such as poor performance and high error rates occur [58]. Three areas have already been intensively studied: reading, learning and driving. First, studies on reading comprehension [45] show that interest and difficulty of the given text decrease mind wandering $[21,26]$. Once the mind wanders, the understanding suffers [56] and the duration of reading increases [21]. Second, mind wandering interrupts learning processes. If thoughts are migrating, the external information from the current surrounding have no influence and can neither be learned nor interpreted [55]. Mind wandering during learning mostly occurs due to a lack of interaction, whereby an active cooperation between students yields the lowest rate of mind wandering [43]. Third, research on driving shows that mind-wandering drivers are at risk of being adversely affected by negligence. When the thoughts are wandering, the reaction time to braking is longer, the velocity higher and the distance to vehicle in the front is shorter compared to attentive drivers [71].

Despite its shortcoming, an increasing body of literature acknowledged that mind wandering also leads to various positive aspects such as (self-) reflection, future planning and creative thinking. Creativity is important for generating new ideas [24]. To be innovative, it is crucial to look at things from various perspectives and to build something unique [24]. Literature shows that mind wandering increases creativity, especially when dealing with complex problems [10]. In this context, results reveal that the deliberate sub-type of mind wandering, which happens with intention and metacognition, positively supports creative performance. In contrast, spontaneous mind wandering, which happens without intention or recognition, is rather negatively related to a creative outcome [4]. Thus, some authors that do not differentiate the sub-types conclude that mind 
wandering is mostly counterproductive [31] leading to the fact that empirical findings are mixed.

Given its ubiquity and complexity, the interest in mind wandering has increased in the IS domain in recent years [46, 63, 67]. Oschinsky et al. show that using hedonic systems (e.g., writing an email) yields in a higher occurrence of mind wandering than using utilitarian systems (e.g., using Facebook) [46]. In addition, Wati et al. refer to mind wandering as prerequisite for the outcome of performance in case of accuracy and efficiency adding different IS task complexities. They figured out that the relation to efficiency is significant, while the relation to accuracy is only significant under high task complexity [67]. Based on their results, Sullivan et al. defined technology-related mind wandering as "task-unrelated thoughts which occur spontaneously and the content is related to the aspects of computer systems" [63]. The authors identified a positive moderating effect between technology-related mind wandering and perceived creativity [63]. Yet, the inconsistent results from the psychological literature of have not yet been discussed in the IS domain.

\subsection{Creativity and Technology Use}

Creativity is a process of creating innovative solutions and novelties [36]. To describe creativity, two essential elements are commonly used. Originality and usefulness [50] or novelty and quality respectively [36]. Novelty is described as the innovation part, to create something new and original. Quality in turn stands for the features of novelty and aims for being good and useful [36]. Therefore, creativity outlines something new with an improved benefit compared to the old solution.

Regarding the process of thoughts, creativity is divided into two different types of thinking. On the one hand, creativity is characterized by divergent thinking, which is a bridge to mind wandering due to the fact of interrupting current on-task thinking with unconstrained thoughts to generate different ideas. On the other hand, it consists of convergent thinking as process of choosing the "best" option of all appearing ideas [29, 69]. Thus, creativity denoted the trial of thinking about ideas and choosing the one solution, which fits best to the requirements of a given problem.

Due to its relevance for innovation and design, IS research on creativity has much potential. For example, Minas and Dennis use the priming effect to perform an idea generation task with creative support systems (CSS), which results in an increased creative output [44]. Moreover, Althuizen and Reichel show that technology enhances the production of novel ideas for problem solving, whereby IT-enabled stimuli providers have a greater effect on creativity than process guides and mind mappers. This stimuli were designed to provide relevant information about the current task by using clues in form of images, sounds, sentences, or words and thus increase creativity [5]. In addition, Lee and Choi indicate that organizational creativity is critical to improve organizational performance [38]. They study the relation between knowledge creation, organizational creativity, and organizational performance. The authors seek to both help firms to strengthen their performance and managers to find the right worker for knowledge creation and thus improve knowledge management.

Through the connectivity of individuals, social interaction and idea sharing become possible in technological environments and in a location- and time-independent way. Consequently, creativity is highly relevant during collaborative tasks as individual knowledge and the sharing of it helps improve team creativity [65]. For example, novelty and the quality of creative output were researched with the aid of technology in form of online brainstorming $[12,16,25,42]$ in collaborative work in connection with cognitive stimulation. Bhagwatwar et al. show that priming within a three-dimensional virtual environment increase the quality of ideas regarding to a greater breadth and depth [12]. This phenomenon is also shown by Dennis et al. who indicate that achievement priming allows people to generate more creative and unique ideas compared to neutral priming [16].

While previous literature has spent considerable efforts to understand mind wandering and creativity isolated, there is only little research that investigates this relationship in detail. Since an increasing number of jobs require a significant amount of creativity, a better understanding of this relationship is both promising for literature and relevant for practice. Against this background, we seek to shed further light into this phenomenon by raising the following research question:

RQ: Does a lengthy interruption while using technology fosters more mind wandering and thus more creativity compared to a short interruption?

\section{Research Model}

In order to address our research question, we propose a research model that hypothesizes the relationship between technology use, which we vary in terms of the length of the interruptions. Moreover, we include mind wandering as both a mediator and a moderator (c.f. 
Figure 1). On the one hand, mind wandering is triggered by interruption and has direct impact on the creative output. On the other hand, mind wandering influence the relation between the interruption impact and the creative output.

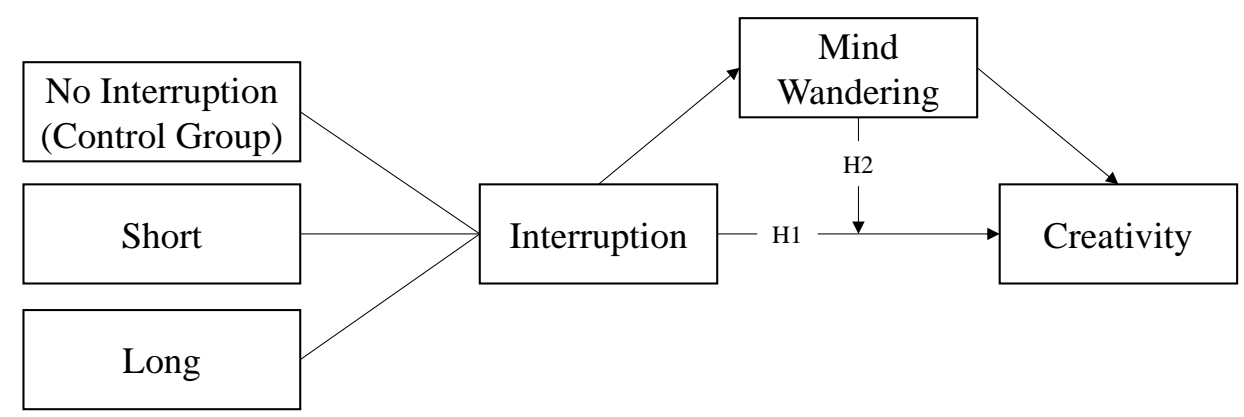

Figure 1. Research Model

Research suggests that ideation processes require nondemanding environments, in form of divergent thinking [29]. Whereby this "can significantly affect individuals" intrinsic motivation to engage in an activity, which in turn affects their creativity" (p. 257) [51]. Interruptions of a primary task serve as the basis for such a non-demanding environment. Consequently, we assume that interruptions influence the occurrence of mind wandering [37, 39], because the attention of the primary task can shift towards taskunrelated thoughts more easily as time passes [22]. This is also in line with Wang et al. who suggest that under certain circumstances creativity is enhanced through interruptions [66].

According to the goal-activation model [6], time is a critical component when it comes to new goals. For the different duration of both interruptions, we relate to literature, which also used a single interruption in experimental setting [27, 35]. Therefore, interruptions that occur for a short duration of time do not lead to the formulation of a new goal. In our context, we assume that short interruptions are not necessarily related to mind wandering episodes, because our working memory can still stick to the original goal (i.e., the primarily task). In contrast, in cases of longer interruptions, the individuals are much more likely to let the mind wander and even forget their initial taskrelated goals. Similarly to this line of thought, Risko et al. demonstrate that with increasing time, the probability of mind wandering increases [49]. Also, Baird et al. indicate an encouraging effect on creativity after resting time [10]. Against this background, we propose our first hypothesis $(\mathrm{H} 1)$ :

H1a: Interruptions lead to a higher degree of creativity compared to no interruption.

H1b: $\quad$ Long interruptions lead to a higher degree of creativity compared to short interruptions.
Cognitive concepts such as mind wandering, mindfulness and cognitive absorption are commonly used as an accelerator between relationships (e.g., [17]). For that reason, previous research has included mind wandering as a moderator between technology use and performance [67]. In line with existing studies on the relationship between mind wandering and creativity, we propose an accelerating effect between task-interruption and creativity. In specific, we assume that the relationship between interruption and creativity is further strengthened through mind wandering. Consequently, we hypothesize that:

$\mathrm{H}_{2}$ : $\quad$ The relationship between interruptions and creativity is accelerated by mind wandering.

\section{Methodology}

\subsection{Experimental Design}

To test our hypothesis, we propose a within-design laboratory experiment with three conditions. A withindesign is most suitable for this endeavor, because episodes of mind wandering can vary within individuals over time [28]. Data will be collected from healthy students from middle-size universities. All participants get a financial compensation.

\subsection{Experimental Task}

At the beginning, the experimenter welcomes the participants and gives them an explanation of the process. Then a brief introduction to the program, which is used in the experiment, is given. We will use the web-based systems PsychoPy3 [47], that is designed for psychological experiments such as the proposed one. 
Afterwards, the participants are introduced to the task. We choose the title task, because it has already been used in similar research settings [30]. The idea of the title task is to find a variety of alternative titles for well-known covers (e.g., for books or movies) [4]. Each participant has to do six tasks in a row. For that reason, we not only use book covers but also covers from well-known music titles. In specific, we select the popular covers from current movies (i.e., "Star Wars: The Rise of Skywalker" and "Avengers: Endgame") that are similar in genre to allow a comparison. For books, we choose "The Lord of the Rings: The Return of the King" and "Harry Potter and the Order of the Phoenix", which are also from the same genre. Finally, we chose two music covers, namely "AC/DC: Highway to Hell" and "Bon Jovi: It's my life".

Within the experimental task, participants are asked to create as many alternatives as possible and write them down after they see the original title. This procedure of creative brain storming and solution identification is explored in previous literature on creativity in IS research $[5,16,25,42]$. For each task, the participant has 5 minutes to write down alternative titles. To strengthen the validation of the creative task, two researchers will evaluate the results independently. In specific, we will score the creative output(usefulness and originality) separately on a 5point Likert scale ranging from "not at all original" to "highly original" $[4,50,53,70]$ and from "not at all useful" to "highly useful" $[36,50]$. A combination of both dimensions is used to measure the overall creativity of the participant.

\subsection{Manipulation}

Previous literature indicates a range from $30 \mathrm{sec}$ to $165 \mathrm{sec}$ [27] for a single interruption during an experiment setting. Consequently, we include an interruption about 30 seconds and a longer interruption with 120 seconds. We assume that a longer duration of task interruption triggers more mind wandering than a short one. For visualization of these interruptions and to make it understandable for the participants, we include a visual loading screen when the interruption occurs (Figure 2). To indicate that the interruption is an immediate part of the experiment and not an error message within the software, an instruction "Please wait." above the loading bar is implemented. The exact period of time in which the loading bar is completed is not known by participants and can only be estimated by the pace of completion. After this, both groups can continue with their ideas within the remaining time.
Immediately after the processing time, participants are instructed to complete a final questionnaire. It measures mind wandering and perceived creativity as well as the demographics. It takes about 7 minutes. Finally, the instructor thanks the participants and hands over their compensation.

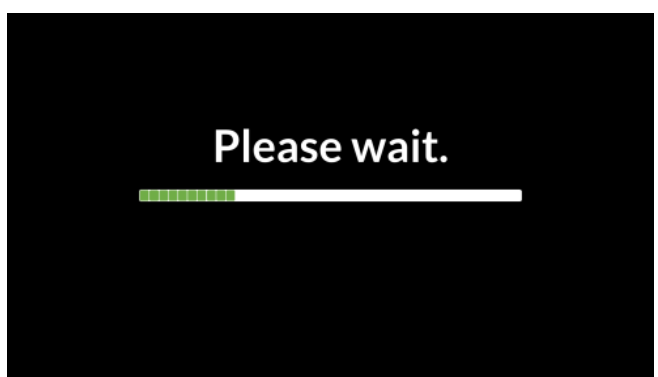

Figure 2. Example of the interruption

\subsection{Measurement Instruments}

In order to identify the occurrence of mind wandering in the experiment, a self-report measurement is obtained by means of a questionnaire, which represents standard in the previous literature [68]. For the measurement of mind wandering, we combine two established item collections [46, 67], which were slightly adjusted to the given circumstances. The selected items (Table 1) are all concerned with divergent thinking and denote taskunrelated thoughts. Additionally, it is to note that all items are related to the state of mind wandering and do not describe mind wandering as a trait. This is due to the fact, that the experiment investigates the situationdependent influence on creative output and not the general attitude concerning wandering thoughts.

\section{Table 1. Mind Wandering Items}

\begin{tabular}{|c|l|}
\hline & $\begin{array}{l}\text { When using the technology to brainstorm for } \\
\text { ideas creation ... }\end{array}$ \\
\hline MW1 & $\begin{array}{l}\ldots, \text { I thought about something, which was } \\
\text { not related to the booking process. }\end{array}$ \\
\hline MW2 & $\begin{array}{l}\text {.., I found myself distracted by other } \\
\text { things. }\end{array}$ \\
\hline MW3 & $\ldots$, I had so many things in mind. \\
\hline MW4 & $\begin{array}{l}\ldots, \text { I got easily distracted by unnecessary } \\
\text { information. }\end{array}$ \\
\hline MW5 & $\ldots$, my mind wandered. \\
\hline MW6 & $\ldots$, I was daydreaming. \\
\hline MW7 & $\begin{array}{l}\ldots, \text { I did not concentrate on the creation } \\
\text { process. }\end{array}$ \\
\hline
\end{tabular}

In addition to the evaluation of the title task, creativity is determined by means of a self-report questionnaire. The measurement items refer to the generation of novel and innovative ideas and are also 
taken from established previous literature [33]. A complete overview of the remaining items is provided in Table 2 (Appendix A).

\subsection{Preliminary results}

Due to the ambivalence of the relationship between mind wandering and creativity [4, 60], we analyzed survey data that relate to our research model. In specific, we seek to provide initial evidence on the usefulness of our intended manipulation and its effect on creativity. For that purpose, we used established measurement scales for related constructs, namely perceived control [3], temporal disassociation [3], and perceived creativity [33].

We used data from 81 individuals, on average aged $30(\mathrm{M}=30.0, \mathrm{SD}=11.0)$, with 42 percent female and 58 percent male respondents, with an average working experience of 8 years $(\mathrm{M}=8.44, \mathrm{SD}=10.7)$.

In order to understand whether the planned manipulation works as intended, we investigate the relationship between perceived control and temporal disassociation on mind wandering, because participants have no way to influence the interruption and therefore have a lack of control and are likely to lose their sense of time. While both variables do not measure interruption directly, we argue that it is a good first indicator that provides further information on our proposed hypothesis.

The results of a regression analysis suggest a significant model fit between control and mind wandering $F(1,79)=8.43, p=0.00$, with a significant path coefficient $(b=-.34, p=0.00)$. Similarly, the relationship between temporal disassociation and mind wandering suggests a significant model fit $F(1,79)=4.32, p=0.04$, with a significant path coefficient $(\mathrm{b}=0.21, \mathrm{p}=0.04)$.

These significant relationships can be considered an indicator that the temporal aspect and individual control take a central role in relation to mind wandering. Also, it demonstrates that the point of entry into task-unrelated thoughts is connected to a certain time interval in which the individual drifts away from the current environment to a mental state of inner thoughts, which cannot be controlled by herself/himself. In summary, the results of the regression analysis provide initial evidence related to the first hypothesis $\left(\mathrm{H}_{1 \mathrm{a}}, \mathrm{H}_{1 \mathrm{~b}}\right)$.

To preliminarily investigate whether mind wandering has an impact on creativity, we use the selfreported measures of mind wandering and creativity [4]. The results of a regression analysis suggests a nonsignificant model fit $F(1,79)=0.02, \mathrm{p}=0.89$ and a non-significant relationship between mind wandering and perceived creativity $(\mathrm{b}=0.02, \mathrm{p}=0.89)$.
According to these results, mind wandering has no direct influence on the degree of creativity. A drift of thoughts and thus divergent thinking from the current situation neither positively nor negatively influenced the possible resulting creativity. However, empirical findings in the literature are mixed and need a more thorough investigation.

\section{Discussion}

Despite the importance of mind wandering as a fundamental cognitive process, there is a significant gap in IS literature in terms of a solid understanding of its role mind wandering in IS-related phenomena. We address this gap by proposing a research model that integrates mind wandering as a moderator and a mediation between the length of interruption and creativity.

The length of the interruptions is a critical concern here, because the length can have a significant impact on the primary task. Long interruptions are assumed to make it difficult to return to the primary task. Previous literature has suggested that this resumption lag [7] varies between 1 and 24 minutes [1]. Consequently, an effective interruption leads to a considerable amount of time to bring the user's attention back. This research, which includes a variation of interruption length, can therefore informs future research its impact on specific outcome variables such as mind wandering.

Previous literature also stressed the importance of intuition and intuitive action. For example, Eling et a. demonstrate that an intuitive analysis yield in quicker decisions [19]. In case of our proposed experiment, mind wandering can similarly stimulate this kind of intuitive action when participants generate titles quicker. As a consequence, this research has also the potential to contribute to a better understanding of intuition.

Based on our results, we can derive several implications for research and practice. For theory, our study contributes to a better understanding of mind wandering while using technology. Moreover, while research in the domain of psychology has shown that there is a positive relationship between mind wandering and creativity [4, 10], IS literature lacks empirical evidence on this relationship in terms of technology use. Consequently, this research contributes to existing IS literature that has primarily concentrated on on-task task performance $[63,67]$ by focusing on task creativity and innovative output induced by off-task thoughts.

An interruption while using technology is commonly considered as a negative as well as stressful 
aspect, which reduces task-performance $[2,8]$. In line with other authors, who already shifted their attention towards positive outcomes of interruptions [2], we propose another perspective on the value of interruptions at work. While others have argued that interruptions are disruptive [9, 27], we suggest that interruptions can lead to mind wandering activities which in turn lead to the positive outcome of creating new ideas. This distinguishes it from other creative processes, because mind wandering is task-unrelated and unguided and has gained only little attention so far. Therefore, we seek to contribute to existing literature on interruptions and its consequences from a new perspective.

This research is also promising for the development and design of IS. Interruptions as suggested here can be integrated in any class of system. We argue that based on its effects on mind wandering, interruptions are most likely beneficial in systems that are used in creative work. In contrast, systems that are designed for routine work and tasks that requires a high degree of attention should avoid any kind of distraction.

Since we focus on a cognitive process, this research can also inform IS design when it comes to neuroadaptive systems [48, 64]. Therefore, systems that use neurophysiological data to detect mind wandering episodes can maintain (or avoid) interruptions to either foster mind wandering or reduce it. This topic travels well with the rising interest in NeuroIS research and can also learn from integrating objective neuroimaging measures to further elaborate on the validity of measuring cognitive concepts such as mind wandering and creativity.

This research also has important implications for practice. Above all, we argue that mind wandering episodes can be valuable at work. Since creativity is a pivotal human asset, this research can inform practice on how to design workplaces and workplace IT. While technology is mostly designed to keep our attention (see for instance [54]), research shows that is time to think about alternatives. Particularly, organizations that depend on creative thinking should take concepts like mind wandering and daydreaming into consideration when designing future-oriented jobs.

\section{Limitations and Outlook}

As every research, this study comes with some limitations that should be addressed in future research. First, we used survey data to get preliminary insights on the usability of our research model. Consequently, future research should go one step further by carrying out an experimental study with an experimental task to get further insights. This is also relevant in terms of the manipulation. More empirical insights are required to justify the length of the interruption.

Like other studies that focus on cognitive processes, self-reported measures can be biased. This can be particularly relevant in terms of mind wandering because participants are not always aware that their mind is wandering or can recall their train of thoughts. This relates to the fact that mind wandering is considered the standard process in nearly every daily activity [34]. Thus, the triangulation of certain measurement methods may become more important in future research.

Finally, this research is primarily motivated with previous insights from cognitive sciences and mind wandering in specific. Consequently, more insights can be generated by extend this perspective by integration other theories from the creativity literature. For example, the theory of inventive problem solving (TRIZ) [41] and concept-knowledge theory (C-K theory) [32]) are promising candidates to justify potential outcomes better. This is particularly relevant when it comes to the distinction between divergent and convergent thinking [29, 69], which contribute a substantial part to the idea creation process.

Since creative processes are highly important for many knowledge workers, this research is most promising in a field setting with a strong external validity.

\section{References}

[1] Addas, S. and A. Pinsonneault, "The Many Faces of Information Technology Interruptions: A Taxonomy and Preliminary Investigation of Their Performance Effects", Information Systems Journal, 25(3), 2015, pp. 231-273.

[2] Addas, S. and A. Pinsonneault, "E-Mail Interruptions and Individual Performance: Is There a Silver Lining?", MIS Quarterly, 42(2), 2018, pp. 381-405.

[3] Agarwal, R. and E. Karahanna, "Time Flies When You're Having Fun: Cognitive Absorption and Beliefs about Information Technology Usage", MIS Quarterly, 24(4), 2000, pp. 665-694.

[4] Agnoli, S., M. Vanucci, C. Pelagatti, and G.E. Corazza, "Exploring the Link Between Mind Wandering, Mindfulness, and Creativity: A Multidimensional Approach", Creativity Research Journal, 30(1), 2018, pp. 41-53.

[5] Althuizen, N. and A. Reichel, "The Effects of IT-Enabled Cognitive Stimulation Tools on Creative Problem Solving: A Dual Pathway to Creativity", Journal of Management Information Systems, 33(1), 2016, pp. 11-44. 
[6] Altmann, E., "Memory for Goals: An Activation-Based Model", Cognitive Science, 26(1), 2002, pp. 39-83.

[7] Altmann, E.M. and J.G. Trafton, "Task Interruption: Resumption Lag and the Role of Cues", Proceedings of the 26th Annual Conference of the Cognitive Science Society, 2004, pp. 43-48.

[8] Bailey, B.P., J.A. Konstan, and J.V. Carlis, "Measuring the Effects of Interruptions on Task Performance in the User Interface", in IEEE International Conference on Systems, Man, and Cybernetics.

[9] Bailey, B.P., J.A. Konstan, and J.V. Carlis, "The Effects of Interruptions on Task Performance, Annoyance, and Anxiety in the User Interface", in Proceedings of IFIP TC.13 International Conference on Human-Computer Interaction.

[10] Baird, B., J. Smallwood, M.D. Mrazek, J.W.Y. Kam, M.S. Franklin, and J.W. Schooler, "Inspired by Distraction: Mind Wandering Facilitates Creative Incubation", Psychological Science, 23(10), 2012, pp. 1117-1122.

[11] Baird, B., J. Smallwood, and J.W. Schooler, "Back to the Future: Autobiographical Planning and the Functionality of Mind-Wandering", Consciousness and Cognition, 20(4), 2011, pp. 1604-1611.

[12] Bhagwatwar, A., A. Massey, and A. Dennis, "Contextual Priming and the Design of 3D Virtual Environments to Improve Group Ideation", Information Systems Research, 29(1), 2018, pp. 169-185.

[13] Buckner, R.L. and J.L. Vincent, "Unrest at Rest: Default Activity and Spontaneous Network Correlations", NeuroImage, 37(4), 2007, pp. 1091-1099.

[14] Christoff, K., A. Gordon, and R. Smith, "The Role of Spontaneous Thought in Human Cognition", Psychology Press, 2011, pp. 1-43.

[15] Christoff, K., Z.C. Irving, K.C.R. Fox, R.N. Spreng, and J.R. Andrews-Hanna, "Mind-wandering as Spontaneous Thought: A Dynamic Framework", Nature Reviews Neuroscience, 17(11), 2016, pp. 718-731.

[16] Dennis, A.R., R.K. Minas, and A.P. Bhagwatwar, "Sparking Creativity: Improving Electronic Brainstorming with Individual Cognitive Priming", Journal of Management Information Systems, 29(4), 2013, pp. 195-216.

[17] Dernbecher, S. and R. Beck, "The Concept of Mindfulness in Information Systems Research: A MultiDimensional Analysis", European Journal of Information Systems, 26(2), 2017, pp. 121-142.

[18] Dijksterhuis, A. and T. Meurs, "Where Creativity Resides: The Generative Power of Unconscious Thought", Consciousness and Cognition, 15(1), 2006, pp. 135-146.

[19] Eling, K., F. Langerak, and A. Griffin, "The Performance Effects of Combining Rationality and Intuition in Making Early New Product Idea Evaluation Decisions",
Creativity and Innovation Management, 24(3), 2015, pp. $464-477$.

[20] Engert, V., J. Smallwood, and T. Singer, "Mind Your Thoughts: Associations Between Self-Generated Thoughts and Stress-Induced and Baseline Levels of Cortisol and Alpha-Amylase", Biological Psychology, 103, 2014, pp. 283-291.

[21] Feng, S., S. D’Mello, and A. C Graesser, "Mind Wandering While Reading Easy and Difficult Texts", Psychonomic Bulletin \& Review, 20(3), 2013, pp. 586-592.

[22] Fisher, C. d., "Effects of External and Internal Interruptions on Boredom at Work: Two Studies", Journal of Organizational Behavior, 19(5), 1998, pp. 503-522.

[23] Fox, K.C.R. and K. Christoff, eds., The Oxford Handbook of Spontaneous Thought: Mind-Wandering, Creativity, and Dreaming, Oxford University Press, New York, 2018.

[24] Franken, R.E., Human Motivation, Brooks/Cole Publishing Company, 1994.

[25] Garfield, M.J., N.J. Taylor, A.R. Dennis, and J.W. Satzinger, "Research Report: Modifying Paradigms Individual Differences, Creativity Techniques, and Exposure to Ideas in Group Idea Generation", Information Systems Research, 12(3), 2001, pp. 322-333.

[26] Giambra, L. and A. Grodsky, "Task-Unrelated Images and Thoughts While Reading", in Imagery Curr. Perspect. 1989.

[27] Gillie, T. and D. Broadbent, "What Makes Interruptions Disruptive? A Study of Length, Similarity, and Complexity", Psychological Research, 50(4), 1989, pp. 243-250.

[28] Golchert, J., J. Smallwood, E. Jefferies, P. Seli, J.M. Huntenburg, F. Liem, M.E. Lauckner, S. Oligschläger, B.C. Bernhardt, A. Villringer, and D.S. Margulies, "Individual Variation in Intentionality in the Mind-Wandering State is Reflected in the Integration of the Default-Mode, FrontoParietal, and Limbic Networks", NeuroImage, 146, 2017, pp. 226-235.

[29] Guilford, J.P., The Nature of Human Intelligence, McGraw-Hill, New York, 1967.

[30] Guilford, J.P., Intelligence, Creativity and Their Educational Implications, Edits Pub, Sun Diego, 1968.

[31] Hao, N., M. Wu, M.A. Runco, and J. Pina, "More Mind Wandering, Fewer Original Ideas: Be Not Distracted During Creative Idea Generation", Acta Psychologica, 161, 2015, pp. 110-116.

[32] Hatchuel, A. and B. Weil, "C-K Theory: Notions and Applications of a Unified Design Theory", Herbert Simon International Conference on Design Sciences, 2002, pp. 122. 
[33] Hirst, G., D. van Knippenberg, C.-h. Chen, and C.A. Sacramento, "How Does Bureaucracy Impact Individual Creativity? A Cross-Level Investigation of Team Contextual Influences on Goal Orientation-Creativity Relationships", Academy of Management Journal, 54(3), 2011, pp. 624641.

[34] Killingsworth, M.A. and D.T. Gilbert, "A Wandering Mind is an Unhappy Mind", Science, 330(6006), 2010, p. 932 .

[35] Kreifeldt, J.G. and M.E. Mccarthy, "Interruption as a Test of the User-Computer Interface", in JPL Proc. of the 17th Ann. Conf. on Manual Control.

[36] Kühn, S., S.M. Ritter, B.C.N. Müller, R.B. van Baaren, M. Brass, and A. Dijksterhuis, "The Importance of the Default Mode Network in Creativity: A Structural MRI Study", The Journal of Creative Behavior, 48(2), 2014, pp. 152-163.

[37] Kuschpel, M.S., S. Liu, D.J. Schad, S. Heinzel, A. Heinz, and M.A. Rapp, "Differential Effects of Wakeful Rest, Music and Video Game Playing on Working Memory Performance in the n-Back Task", Frontiers in Psychology, 6, 2015.

[38] Lee, H. and B. Choi, "Knowledge Management Enablers, Processes, and Organizational Performance: An Integrative View and Empirical Examination", Journal of Management Information Systems, 20(1), 2003, pp. 179 228.

[39] Lipitz, S.R., X. Liu, and A. Gutchess, "Self-Referential Memory Encoding and Mind- Wandering in Younger and Older Adults", Open Psychology, 1(1), 2018, pp. 58-68.

[40] Madore, K.P., H.G. Jing, and D.L. Schacter, "Divergent Creative Thinking in Young and Older Adults: Extending the Effects of an Episodic Specificity Induction", Memory \& Cognition, 44(6), 2016, pp. 974-988.

[41] Mann, D., "An Introduction to TRIZ: The Theory of Inventive Problem Solving", Creativity and Innovation Management, 10(2), 2001, pp. 123-125.

[42] Massetti, B., "An Empirical Examination of the Value of Creativity Support Systems on Idea Generation", MIS Quarterly, 20(1), 1996, pp. 83-97.

[43] Mills, C., S. D’Mello, N. Bosch, and A.M. Olney, "Mind Wandering During Learning with an Intelligent Tutoring System", in Artificial Intelligence in Education.

[44] Minas, R.K. and A.R. Dennis, "Visual Background Music: Creativity Support Systems with Priming", Journal of Management Information Systems, 36(1), 2019, pp. 230258.

[45] Mooneyham, B.W. and J.W. Schooler, "The Costs and Benefits of Mind-Wandering: A Review", Canadian Journal of Experimental Psychology, 67(1), 2013, pp. 11-18.
[46] Oschinsky, F., M. Klesel, N. Ressel, and B. Niehaves, "Where Are Your Thoughts? On the Relationship between Technology Use and Mind Wandering", in Proceedings of the 52nd Hawaii International Conference on System Sciences. 2019.

[47] Peirce, J., J.R. Gray, S. Simpson, M. MacAskill, R. Höchenberger, H. Sogo, E. Kastman, and J.K. Lindeløv, "PsychoPy2: Experiments in Behavior Made Easy", Behavior Research Methods, 51(1), 2019, pp. 195-203.

[48] Riedl, R. and P.-M. Léger, Fundamentals of NeuroIS. Information Systems and the Brain., Springer, Berlin, Heidelberg, 2016.

[49] Risko, E.F., N. Anderson, A. Sarwal, M. Engelhardt, and A. Kingstone, "Everyday Attention: Variation in Mind Wandering and Memory in a Lecture", Applied Cognitive Psychology, 26(2), 2012, pp. 234-242.

[50] Runco, M.A. and G.J. Jaeger, "The Standard Definition of Creativity", Creativity Research Journal, 24(1), 2012, pp. 92-96.

[51] Said-Metwaly, S., W. van den Noortgate, and E. Kyndt, "Approaches to Measuring Creativity: A Systematic Literature Review", Creativity. Theories - Research Applications, 4(2), 2017, pp. 238-275.

[52] Seli, P., M.J. Kane, J. Smallwood, D.L. Schacter, D. Maillet, J.W. Schooler, and D. Smilek, "Mind-Wandering as a Natural Kind: A Family-Resemblances View", Trends in Cognitive Sciences, 22(6), 2018, pp. 479-490.

[53] Silvia, P.J., B.P. Winterstein, J.T. Willse, C.M. Barona, J.T. Cram, K.I. Hess, J.L. Martinez, and C.A. Richard, "Assessing Creativity With Divergent Thinking Tasks: Exploring the Reliability and Validity of New Subjective Scoring Methods", Psychology of Aesthetics, Creativity, and the Arts, 2(2), 2008, pp. 68-85.

[54] Singer, N., "Can't Put Down Your Device? That's by Design", The New York Times, 2015.

[55] Smallwood, J., D.J. Fishman, and J.W. Schooler, "Counting the Cost of an Absent Mind: Mind Wandering as an Underrecognized Influence on Educational Performance", Psychonomic Bulletin \& Review, 14(2), 2007, pp. 230-236.

[56] Smallwood, J., M. McSpadden, and J.W. Schooler, "When Attention Matters: The Curious Incident of the Wandering Mind", Memory \& Cognition, 36(6), 2008, pp. 1144-1150.

[57] Smallwood, J., M. Obonsawin, and D. Heim, "Task Unrelated Thought: The Role of Distributed Processing", Consciousness and Cognition, 12(2), 2003, pp. 169-189.

[58] Smallwood, J. and J. Schooler, "The Science of Mind Wandering: Empirically Navigating the Stream of Consciousness", Annual Review of Psychology, 66, 2015, pp. $487-518$. 
[59] Smallwood, J. and J.W. Schooler, "The Restless Mind", Psychological Bulletin, 132(6), 2006, pp. 946-958.

[60] Smeekens, B.A. and M.J. Kane, "Working Memory Capacity, Mind Wandering, and Creative Cognition: An Individual-Differences Investigation into the Benefits of Controlled Versus Spontaneous Thought", Psychology of Aesthetics, Creativity, and the Arts, 10(4), 2016, pp. 389415.

[61] Smith, S.M., P.T. Fox, K.L. Miller, D.C. Glahn, P.M. Fox, C.E. Mackay, N. Filippini, K.E. Watkins, R. Toro, A.R. Laird, and C.F. Beckmann, "Correspondence of the Brain's Functional Architecture During Activation and Rest", Proceedings of the National Academy of Sciences of the United States of America, 106(31), 2009, pp. 13040-13045.

[62] Sternberg, R.J. and T.I. Lubart, "The Concept of Creativity: Prospects and Paradigms", in Handbook of Creativity, R.J. Sternberg, Editor. 1999. Cambridge University Press: Cambridge.

[63] Sullivan, Y., F. Davis, and C. Koh, "Exploring Mind Wandering in a Technological Setting", in Proceedings of the Thirty Sixth International Conference on Information Systems. 2015: Fort Worth, United States of America.

[64] vom Brocke, J., R. Riedl, and P.-M. Léger, "Application Strategies for Neuroscience in Information Systems Design Science Research", Journal of Computer Information Systems, 53(3), 2013, pp. 1-13.

[65] Vreede, T. de, I. Boughzala, G.-J. de Vreede, and R. Reiter-Palmon, "A Model and Exploratory Field Study on Team Creativity", Hawaii International Conference on System Science, 45, 2012, 227-236.

[66] Wang, X., S. Ye, and H.-H. Teo, "Effects of Interruptions on Creative Thinking", in Proceedings of the 35th International Conference on Information Systems. 2014: Auckland.

[67] Wati, Y., C. Koh, and F. Davis, "Can You Increase Your Performance in a Technology-Driven Society Full of Distractions?", in Proceedings of the Thirty Fifth International Conference on Information Systems. 2014: Auckland, New Zealand.

[68] Weinstein, Y., "Mind-Wandering, How Do I Measure Thee with Probes? Let Me Count the Ways", Behavior Research Methods, 50, 2017.

[69] Wiggins, G.A. and J. Bhattacharya, "Mind the Gap: An Attempt to Bridge Computational and Neuroscientific Approaches to Study Creativity", Frontiers in Human Neuroscience, 8(540), 2014, pp. 1-15.

[70] Wilson, R.C., J.P. Guilford, and P.R. Christensen, "The Measurement of Individual Differences in Originality", Psychological Bulletin, 50(5), 1953, pp. 362-370.

[71] Yanko, M.R. and T.M. Spalek, "Driving with the Wandering Mind: The Effect That Mind-Wandering Has on
Driving Performance", Human Factors: The Journal of the Human Factors and Ergonomics Society, 56(2), 2014, pp. 260-269.

\section{Appendix A}

Table 2. Measurement Items

\begin{tabular}{|c|c|}
\hline \multicolumn{2}{|r|}{ Creativity [33] } \\
\hline & During the brainstorming session ... \\
\hline CREA1 & $\begin{array}{l}\text {..., I seek new ideas and ways to solve } \\
\text { problems. }\end{array}$ \\
\hline CREA2 & $\begin{array}{l}\text {..., I generate ideas revolutionary to the } \\
\text { field. }\end{array}$ \\
\hline CREA3 & $\begin{array}{l}\text {..., I think it is a good role model for } \\
\text { innovation/creativity. }\end{array}$ \\
\hline CREA4 & $\begin{array}{l}\text {..., I try new ideas and approaches to a } \\
\text { problem. }\end{array}$ \\
\hline \multicolumn{2}{|r|}{ Temporal Dissociation [3] } \\
\hline & $\begin{array}{l}\text { Please put yourself back in the given } \\
\text { situation. In the experienced situation ... }\end{array}$ \\
\hline TD1 & $\ldots$, I lose track of time. \\
\hline TD2 & ..., time flies. \\
\hline TD3 & $\begin{array}{l}\text {..., I spend more time than I had } \\
\text { intended. }\end{array}$ \\
\hline \multicolumn{2}{|r|}{ Control [3] } \\
\hline & $\begin{array}{l}\text { Please put yourself back in the given } \\
\text { situation. In the experienced situation ... }\end{array}$ \\
\hline $\mathrm{CO} 1$ & ..., I feel in control. \\
\hline $\mathrm{CO} 2$ & ..., I feel that I have no control. \\
\hline $\mathrm{CO} 3$ & ..., I control my interactions. \\
\hline
\end{tabular}

